\title{
Funding shortfall threatens Australian medical training
}

With the number of Australian medical students increasing dramatically, medical and teaching organizations have voiced concerns that the government's funding for clinical training programs falls short of what's needed.

Australia is facing a crucial shortage of doctors and nurses. To meet rising demands, the number of medical students is set to nearly double in the five years from 2007 to 2012. In light of this, the government announced plans in December to spend AUD\$90 million (\$83 million) over four years to support infrastructure projects that expand the capacity of training facilities.

Grants of up to AUD\$5 million will be available to both private and public health providers-including Aboriginal and migrant medical centers-with a special focus on increasing clinical teaching outside of the traditional big-city training hospitals. Additionally, a one-off investment of nearly AUD\$68 million will be provided for training medical students this year.

The money "has stimulated a lot of productive work on new places for students to get their clinical placements outside of conventional teaching hospitals and a pretty strong push to

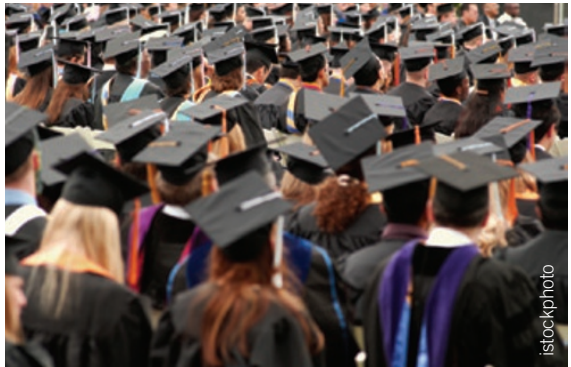

Cap and frown: Med schools unhappy

have multiprofessional experiences as part of those courses," says Michael Hensley, acting president of Medical Deans Australia and New Zealand, which represents the deans of 20 medical schools.

By reinforcing the educational role of clinical placements, the new funding also helps to provide incentives and structural support for medical graduates to undertake $\mathrm{PhD}$ studies, he adds.

This is key, according to Hensley. His organization has projected a potential shortfall in the country's future academic workforce and has asked the Australian National Health and
Medical Research Council and universities to consider strategies to attract medical graduates to plan careers as clinically active academics.

However, the move to broaden the range of host institutions has been questioned by the Australian Medical Students' Association (AMSA), which is concerned that core training centers are in danger of being sidelined by "fashionable facilities."

"While it is essential that we find new and innovate ways to train health care professionals, and this includes private hospitals, we must first put more money towards funding core training facilities at universities and in public hospitals," AMSA president Ross Roberts-Thomson told Nature Medicine.

Even with the new spending on medical training, the Australian Medical Association is forecasting a shortfall of more than 1,500 intern placements by 2012. "Medical training does not stop at the university gate," said association president Andrew Pesce in a statement. "The government must now look at expanding the number of training places for prevocational doctors and specialists."

Simon Grose, Canberra, Australia

\section{Enforcement of new ethics rules pondered in India}

Under new rules, medical practitioners in India cannot accept any gifts or favors from drug companies. The rules, which come from the Medical Council of India and went into effect on 10 December 2009, also bar doctors and their associates from endorsing healthcare products or accepting research grants from the industry without official clearance from authorities such as the country's drug regulators. But skeptics doubt that unethical practices in medicine can be stopped in the absence of laws to penalize the companies that distribute favors.

Ketan Desai, president of the Medical Council of India, the government's watchdog agency, told Nature Medicine he expects the regulations to help curb the unhealthy nexus between doctors and pharmaceutical firms.

The move by the Medical Council of India to enact the rules was prompted by media revelations of several cases of drug companies bribing doctors to promote their products, according to Chandra Gulhati, editor of New Delhi-based Monthly Index of Medical Specialties (MIMS).
"Cars, air conditioners, refrigerators and music systems are routinely gifted to obliging doctors, and paid holiday is nothing new in India," says Gulhati, adding that corporations have taken doctors on pleasure trips to destinations ranging from Bangkok to Turkey. What's more, drug companies reportedly spend huge amounts on conferences of medical associations, adds Gulhati.

"To be frank, all of us do accept some gifts," Gyanshankar Mishra, a chest physician in Nagpur, wrote in his blog. Attending company-sponsored conferences "has become a trend", says Mishra, and companysponsored holidays for physicians and their families are so rampant "I doubt how many of us will follow this [new] code of conduct."

Indian Health Minister Ghulam Nabi Azad announced in late November that a bill would soon be introduced in the country's parliament. Meanwhile, Desai says the Medical Council of India's regulations are already enforceable by state medical councils under existing laws. But George Thomas, editor of the Indian Journal of Medical Ethics, says he is "not aware of enforcement ever being done by state councils, although it is common knowledge that commissions are paid [to doctors] for referrals and lab tests in direct contravention of existing guidelines."

The major culprit in the whole drama is the industry, argues Ishwar Gilada, secretary general of Mumbai-based People's Health Organisation. He dismisses the council's new guidelines as a "public relations exercise" and says malpractices cannot be avoided unless there is a law to punish the erring companies.

Gopal Dabade, co-president of the All India Drug Action Network, says there is no political will to enact a law, "because the government considers the Indian drug industry as very important since it is a major exporter".

Tapan Ray, director general of the Organization of Pharmaceutical Producers of India (OPPI) says a "self regulation system" for its member companies has been in existence since 2000 to process complaints. "Where it is determined that there has been a breach of the OPPI Code, the objective is to correct the matter as rapidly as possible," he told Nature Medicine.

K.S. Jayaraman, Bangalore, India 